\title{
Clutch tectonics and the partial attachment of lithospheric layers
}

\author{
B. Tikoff ${ }^{1}$, Ch. Teyssier ${ }^{2}$, and Ch. Waters ${ }^{1}$ \\ ${ }^{1}$ Department of Geology and Geophysics, University of Wisconsin, Madison, WI 53706, USA \\ ${ }^{2}$ Department of Geology and Geophysics, University of Minnesota, Minneapolis, MN 55455, USA
}

Received: 23 February 2001 - Revised: 23 October 2001 - Accepted: 24 October 2001

\begin{abstract}
Clutch zones, in analogy to the clutch in an automobile, explain the mechanical communication between the necessarily different displacement fields of rheologicallydistinct lithospheric layers. In contrast to detachment zones, these sub-horizontal shear zones act as partial attachment zones between lithospheric layers. Two cases are possible: 1) Top-driven clutch systems, such as in extensional core complexes, in which kinematics are controlled by gravitational forces; or 2) Bottom-driven clutch systems in which kinematics are imposed from below. We focus on three different clutches that are associated with the lithosphere: the crustal brittle/ductile transition, the crust/mantle transition (lower crust), and the lithosphere/asthenosphere transition.

The clutch model predicts coupled crustal (lithospheric?) deformation resulting from bulk flow of the lithospheric and asthenospheric mantle. An indication that orogenic systems are generally bottom-driven, rather than side-driven, is the pervasive sub-horizontal shearing which occurs within the lowermost crust. This model questions several aspects of classical plate tectonics by suggesting that: 1) Vertical displacement gradients are as significant as horizontal displacement gradients; 2) Areas of coherent upper crustal movement (plates?) do not encompass the entire lithosphere; and 3) Orogenic deformation results from bottom, rather than side, boundary conditions.
\end{abstract}

\section{Introduction}

Orogens are typically viewed as resulting from horizontal movements of crustal blocks driven by side boundary conditions, in which deformation results from convergence/divergence of two tectonic plates. However, it is possible that crustal deformation is largely driven from basalboundary conditions, rather than from the side-boundary conditions. McKenzie and Jackson (1983) suggested that

Correspondence to: B. Tikoff (basil@geology.wisc.edu) crustal deformation is driven from below by mantle flow. Using a simple example of vertical-axis rotating blocks in California, they predicted a plate motion very similar to present estimates of transcurrent motion at this boundary. Subsequent surveys show similar results: block-fault rotation accommodates deformation of the plate motion as if applied from below. Because rotation for blocks pinned on the edge differs from that for blocks above a ductile substrate, the rate of block-fault rotation is generally good evidence for the system being driven from below.

The lateral direction of mantle flow is interpreted on the basis of seismic velocity anisotropy found through shearwave (SKS) splitting (e.g. Silver, 1996) and primary-wave fast polarization directions. The dominant cause of this anisotropy is interpreted to be the elastic properties of aligned mantle minerals (Nicolas and Christensen, 1987). The fabric is acquired during crystal-plastic deformation. Mantle anisotropy is commonly coherent with crustal deformation in both active and ancient orogenic zones (e.g. Silver, 1996), suggesting that the anisotropy is acquired during lithospheric deformation. A particularly good example of this phenomenon is the deformation of the continental lithosphere in New Zealand, along the Pacific-Australian plate boundary. Molnar et al. (1999) demonstrated that New Zealand is underlain by a mantle shear zone a few hundred kilometers wide.

The continental lithosphere consists of rheologically distinctive layers, including an upper crust, a lower crust, and an upper (lithospheric) mantle. Lithospheric strength profiles constructed from experimentally-derived flow laws (Fig. 1; e.g. Brace and Kohlstedt, 1980) indicate that these layers respond differently to deformation. The upper crust deforms by brittle processes, the lower crust by crystal-plastic processes, and the upper mantle by potentially both processes. The differing mechanical behavior of these layers is the result of variation in composition, pressure, temperature, or combinations of these parameters. The relative strength of these layers is a continuing source of debate (e.g. Kohlstedt 


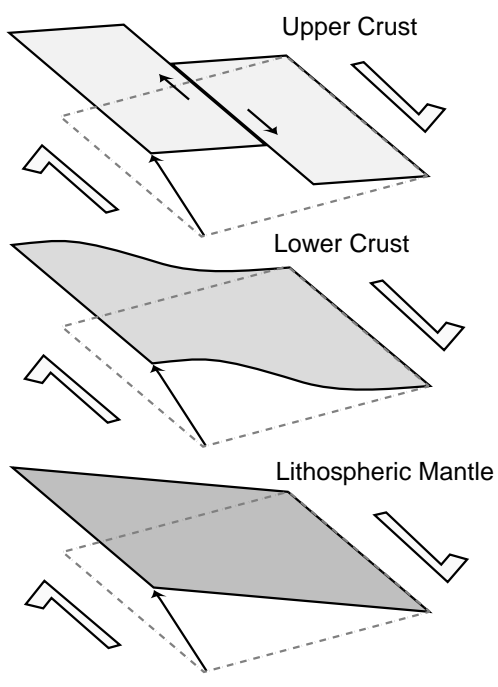

a.

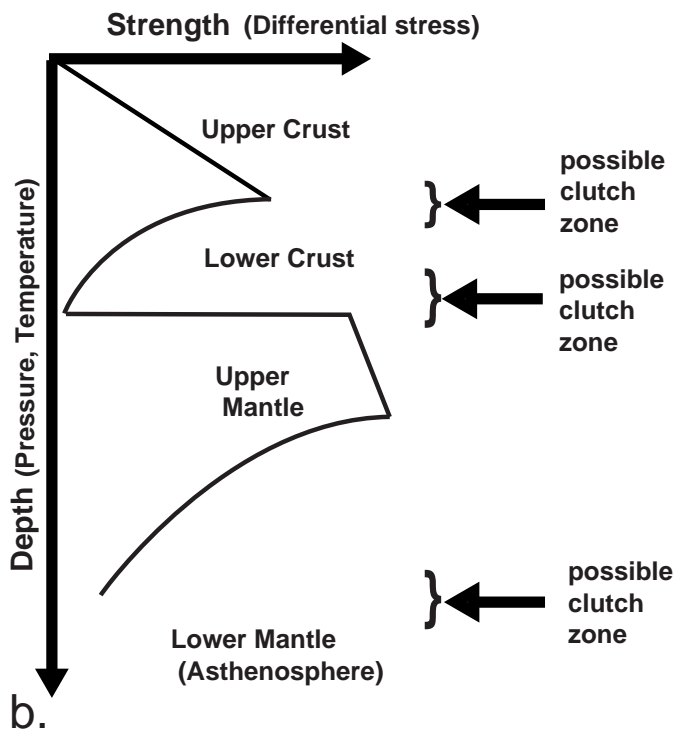

Fig. 1. (a) An example of differing response of the rheological layers in the lithosphere, for a transpressional deformation, with a clutch zone in the lower crust. (b) Lithospheric strength profile (differential stress vs. depth) derived from extrapolation of experimental results. Clutch zones operate where transitions in rheology occur.

et al., 1995). However, the analyses suggest that the lithospheric mantle is the strongest of these layers and, thus, potentially controls deformation in the overlying crust (e.g. Molnar, 1992).

To explore this concept, we propose a conceptual process - clutch tectonics - for the necessarily different response of rheologically-distinct layers. We characterize a clutch zone as a partial attachment between two horizontal lithospheric layers with different displacement fields (Fig. 1). Deformation may be either top-driven or bottom-driven. Mechanical communication exists through these clutch zones despite the rheology differences of the layers.

\section{An automotive analogy}

A clutch zone, a zone of partial attachment, is analogous to the clutch of an automobile (Fig. 2). A clutch allows mechanical continuity between the independently operating wheels and the engine: The wheels can function on a downhill slope without running the engine, and the engine can run without moving the automobile. The question becomes, which system - wheels or engine - moves the car?

If a car moves at a constant speed on flat ground, it becomes impossible to distinguish whether the engine or the wheels move the car when observing their motion (Fig. 2a). It is when there is a difference in motion between the wheels and the engine that a clutch is needed.

We envision two possible cases for activation of a clutch zone: the top layer moves the bottom layer (top-driven system; Fig. 2b), or vice versa (bottom-driven system; Fig. 2c). The top-driven system, with respect to automobiles, can be envisioned as a roll-start. When the clutch is engaged, the movement of the wheels is conveyed to the engine. A top- driven system is also illustrated as driving down a steep mountain road; surviving requires relying on the clutch to couple these systems and allowing the engine to resist the downward motion. In a top-driven system, gravity is the driving force. Core complexes were proposed by Axen et al. (1998) as an example of a lower crustal deformation responding to upper-crustal movement (e.g. a top-driven system: Fig. 3a).

A bottom-driven system is analogous to the situation in which the engine moves the wheels. Starting from a complete stop requires the clutch to slip, which means that the clutch is a deforming zone between the two systems. This requires a discrete motion on an interface, despite the fact that the interface is coupling the systems (a shear zone in a geological setting). Another example is driving uphill in which the wheels are already moving, but will quickly cease to do so unless motion is supplied by the engine. Although the clutch can remain perfectly connected to both the wheels and engine, driving uphill puts additional stress on the clutch. The first sign of a deteriorating clutch is noticed when driving uphill or accelerating (B. Tikoff and C. Teyssier, personal experience, 1988 and 1999 respectively). An example of a geological bottom-driven system may include "active" flow at a mid-ocean spreading ridge (Fig. 3b). In this system, ascent of mantle material causes the outward motion of the overlying lithosphere. Studies of fabric within the Oman ophiolite are consistent with crustal translation and deformation being driven by flow of the underlying mantle material (e.g. Ildefonse et al., 1995; Jousselin et al., 1998).

In summary, top-driven systems, both automotive and geological, are a response to gravitational instability. Bottomdriven systems occur where deformation is driven by flow from below. 


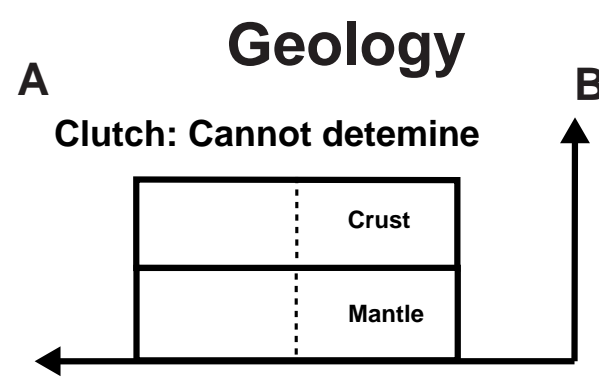

\section{Automotive Analogy}

a.

Driving at constant speed.
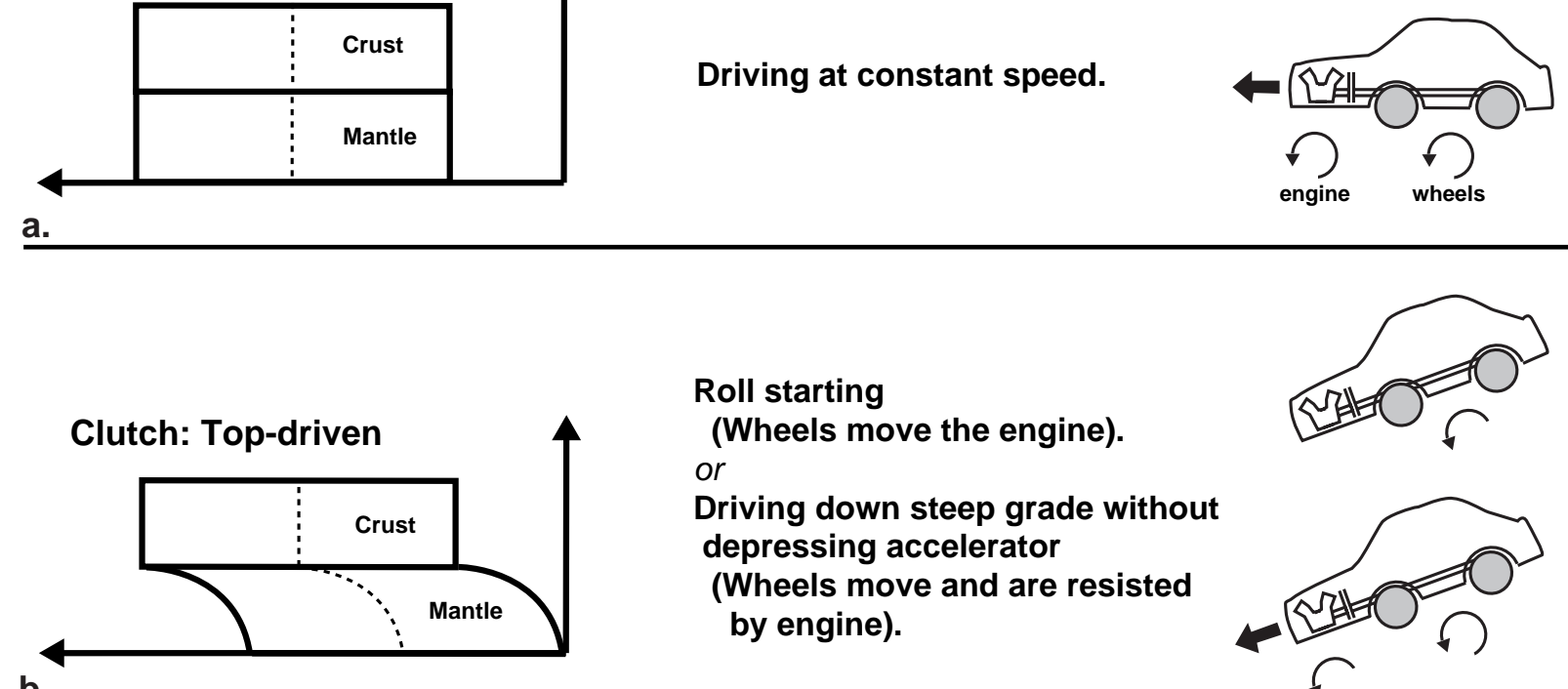

\section{Roll starting}

b.

(Wheels move the engine).

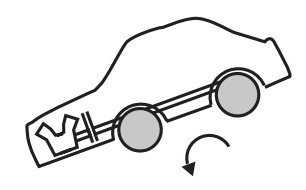

or

Driving down steep grade without depressing accelerator (Wheels move and are resisted by engine).
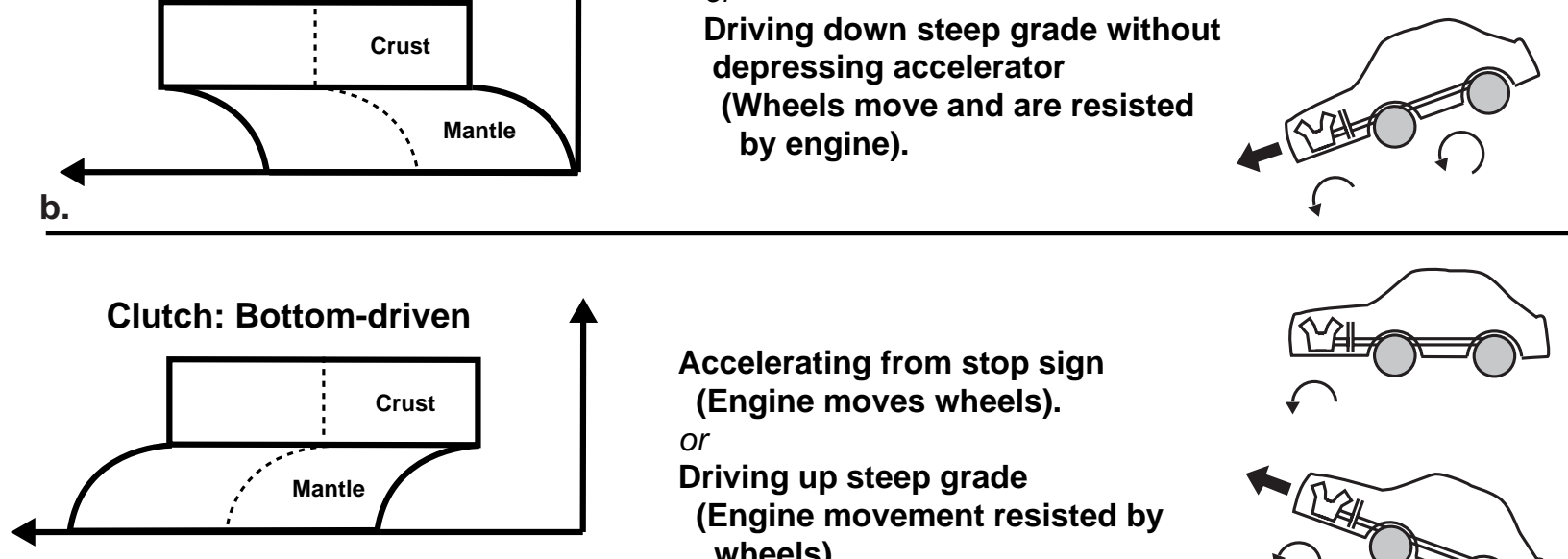

Accelerating from stop sign (Engine moves wheels). or

Driving up steep grade (Engine movement resisted by wheels).

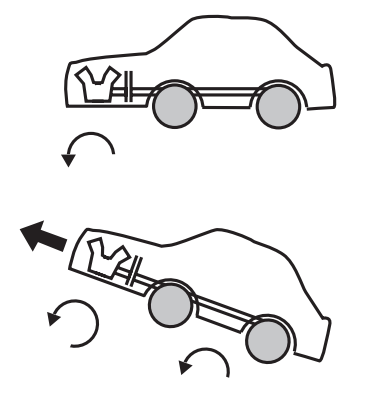

c.

Broken clutch

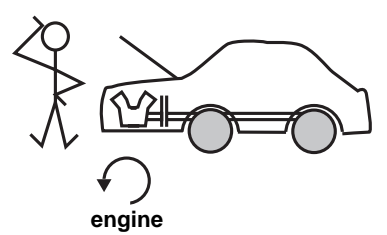

d.

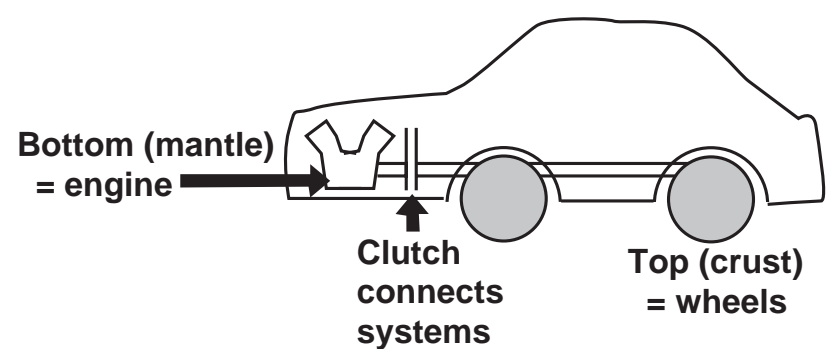

Fig. 2. Automobile analogy for the clutch model. In this example, the wheel represents the motion of the crust while the engine represents the motion of the mantle. (a) If the wheels and the engine move at the same speed, it is impossible to tell which system drives the other (completely attached system). (b) A top-driven clutch zone is similar to roll-starting a car or using the engine to slow down the engine on a steep grade. In both cases, the wheels - through the potential energy - drive the system. (c) A bottom-driven clutch results from the engine moving the wheels, which is most obvious if you are driving uphill or starting from a stopped position. (d) If a detachment occurs, the engine and the wheels operate completely independently of each other. 


\section{Top-driven - core complexes}

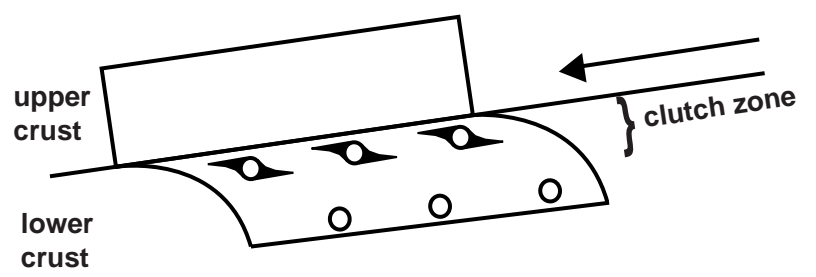

a.

Gravitational collapse - analogy with roll starting

\section{Bottom-driven - active flow at mid-ocean ridge}

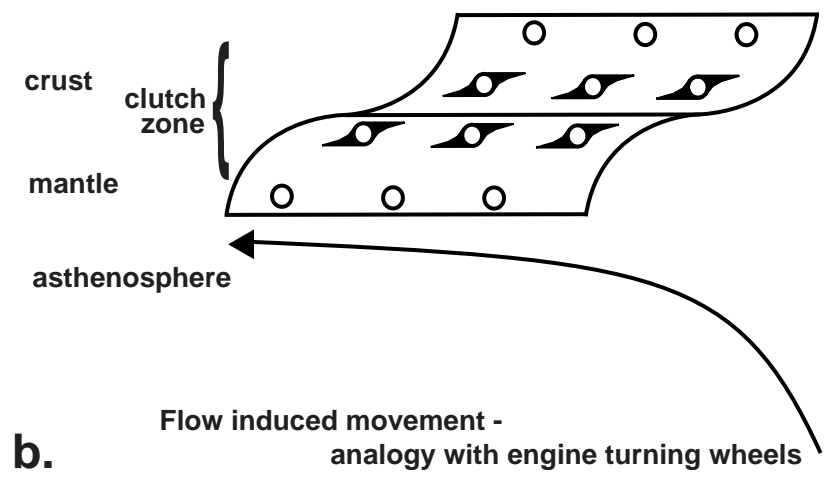

Fig. 3. Geological examples of a top-driven and bottom-driven system for clutch zones. Core complexes, driven by gravitational instability, are top-driven systems. Active flow at a mid-oceanic ridge is an example of a bottom-driven system.

\section{HETEROGENEOUS SIMPLE SHEAR}

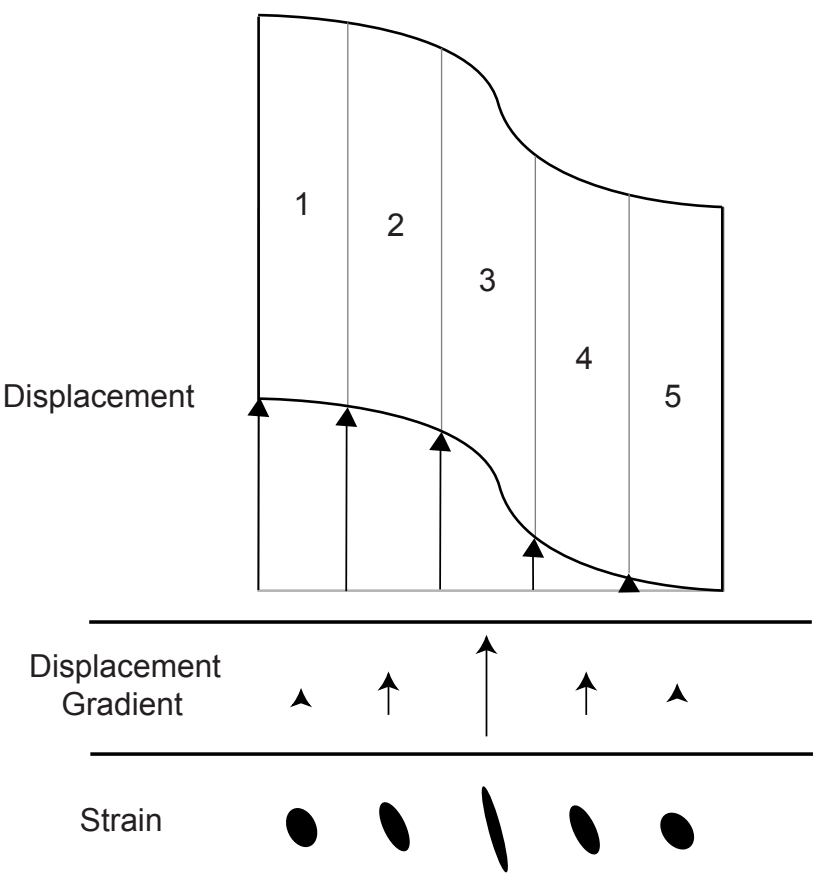

Fig. 4. Map view of heterogeneous simple shear. The amount of strain in each domain correlates to the displacement gradient, not the absolute displacement, within each domain.

\section{Displacement gradients}

The above discussion describes the clutch process as a zone of partial mechanical communication between two horizontal lithospheric layers. The amount of deformation is not directly related to the displacement magnitude of the block.

From a kinematic perspective, it is not the displacement that causes strain, but rather the displacement gradient. This effect is illustrated in Fig. 4 that shows an example of heterogeneous simple shear in map view (equivalent to crosssectional view on end). Domain 1, which has the largest absolute displacement, has the same relatively low strain value as domain 5, which has the smallest absolute displacement. The amount of absolute movement, of course, depends on the reference frame. In contrast, domain 3 has the largest displacement gradient. It is the domain containing the largest displacement gradient that acquires the largest strain magnitude and the best-developed fabrics. In order to maintain continuity across the zones, large displacements require wider deformation zones.

This effect can be considered through the use of loose lines, theoretical material lines that are tracked through deformation (Figs. 5 and 6). Loose lines are traditionally employed in the geological literature for vertical lines in thrust fault systems; we expand this usage to any originally straight line. After deformation, loose lines remain straight for homogeneous deformations or non-straight for heterogeneous deformations. Areas of maximum deformation, and consequently the best-developed fabric, occur where the loose 


\section{LITHOSPHERIC LOOSE LINES}

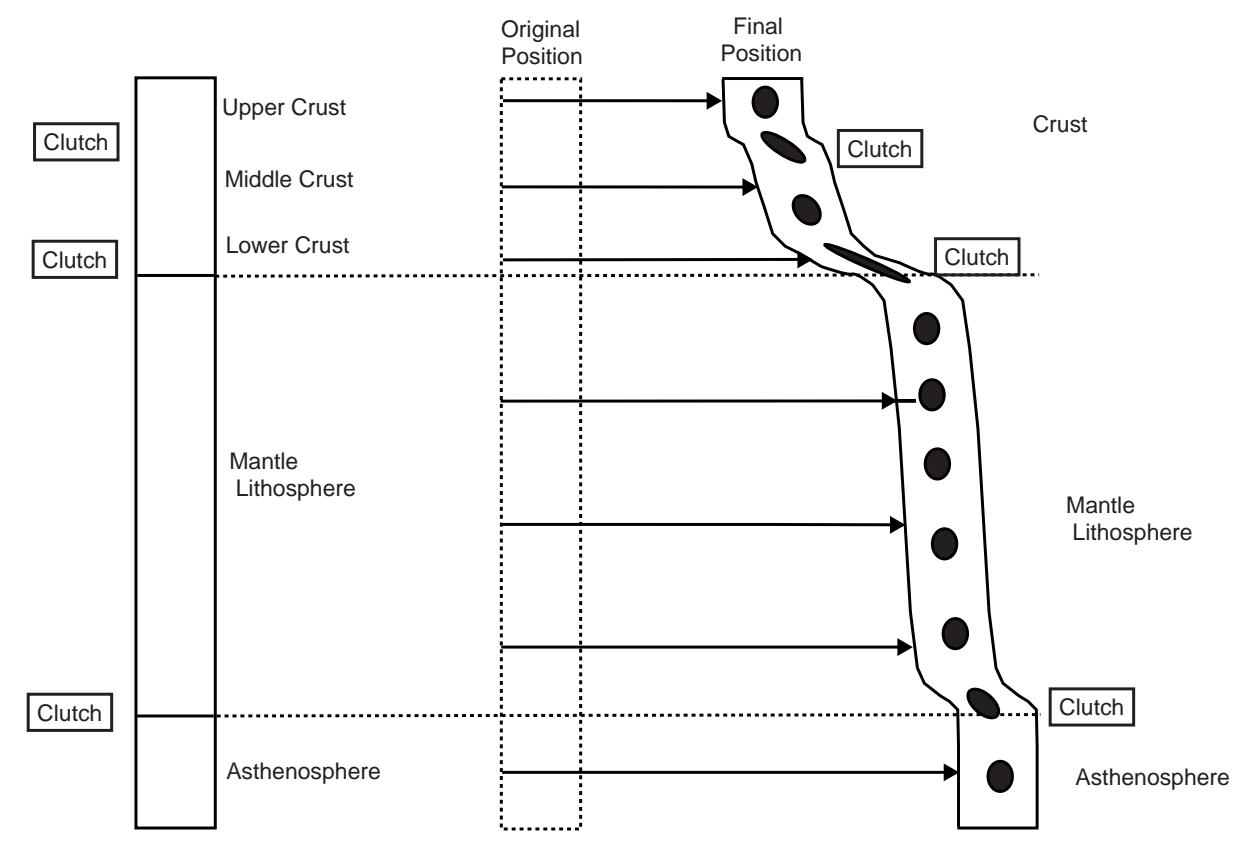

Fig. 5. Cartoon of the response of the lithosphere to deformation. The originally vertical lithospheric loose lines show the occurrence of clutch zones at rheological boundaries.

line is deflected the most (in the absence of an external spin) which often corresponds to the greatest curvature (Fig. 6a). If there is no thinning or thickening of the layers, the deformation in this zone is simple shear and fabrics will rotate toward a sub-horizontal orientation.

In contrast, a discontinuity will discretely offset the loose line (Fig. 6b). Although intense fabric develops in a narrow (m-scale) discontinuity, little fabric development will exist outside this zone as no displacement gradients exist. As such, the discontinuity forms a detachment zone because it removes mechanical communication between adjacent layers.

It is possible to apply these strain concepts to the lithosphere. The vertical displacement gradient is most relevant in determining a clutch mechanism(s). Attachment zones require complete mechanical coupling and no displacement gradients, and hence no fabric development exists at attachment zones. Detachment zones form if there is no mechanical communication between adjacent rheological layers, which result in decollements. In contrast to both of the above, partial attachment (clutch) zones require the formation of shear zones and fabrics. Because of the horizontal layering of the lithosphere, mechanical communication of the layers may result in vertical strain gradients and flat-lying foliation. Given the large displacement gradients, we predict that the shear zones must be relatively thick, on the $100 \mathrm{~m}$ to $\mathrm{km}$-scale. The existence of these sub-horizontal shear zones facilitates the transfer of displacement from one lithospheric layer to another, and implies some inter-layer coupling and mechanical communication.

\section{CROSS-SECTIONAL VIEW (vertical)}

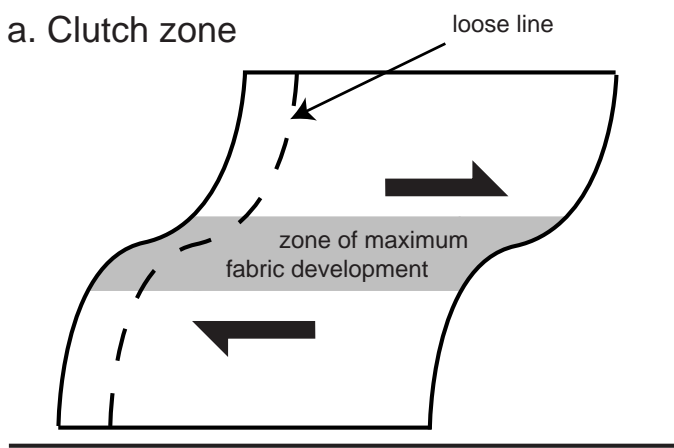

b. Detachment zone

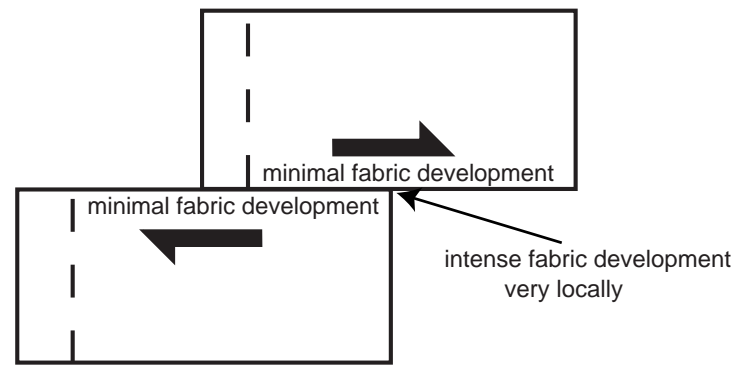

Fig. 6. Cross-sectional view through a theoretical example of rheological layering in the lithosphere. (a) Strain, and consequently fabric development, is greatest where the displacement gradient is the largest. (b) Minimal fabric development is expected in detachment systems. 


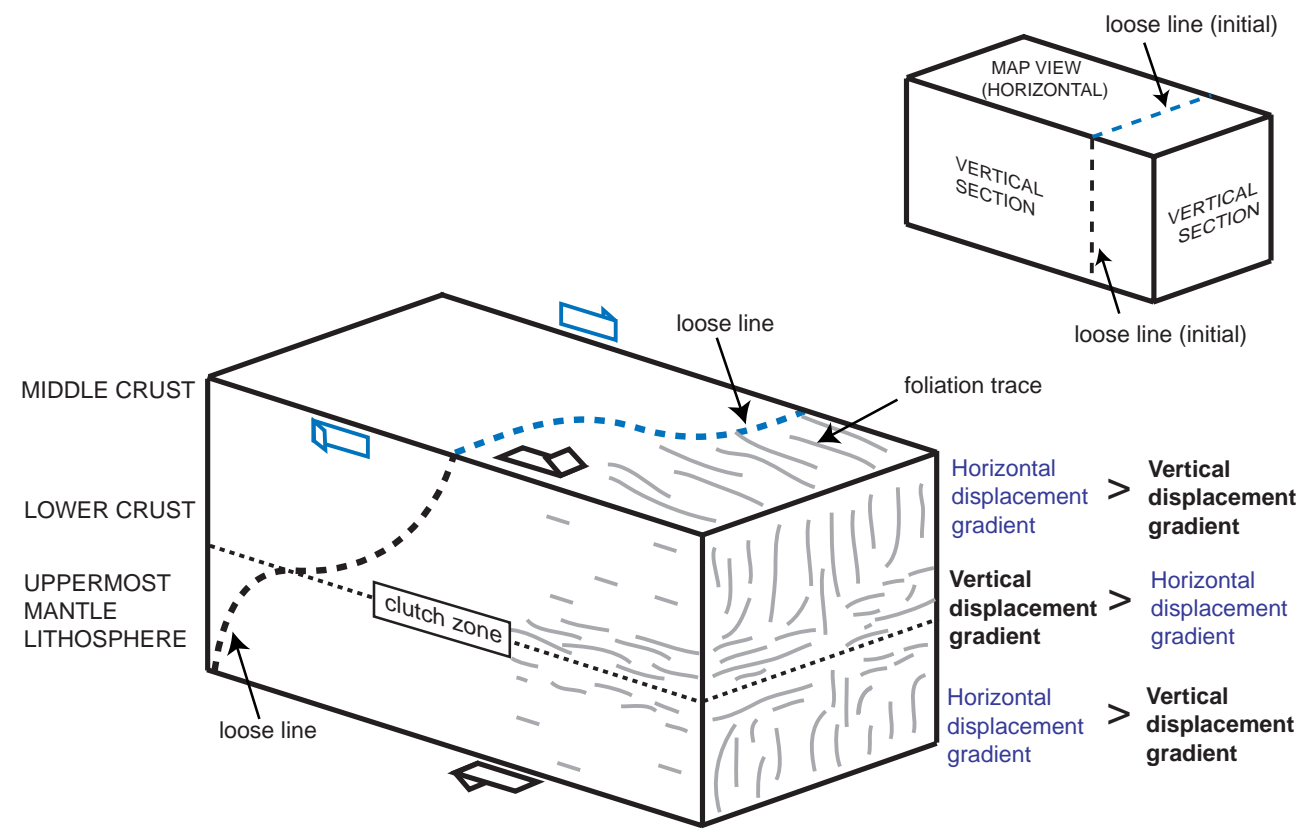

Fig. 7. The effect of vertical and horizontal displacement gradients in a wrench setting as illustrated for the ductile crust and lithospheric mantle. A loose line is a theoretical vertical material line that is followed through deformation. Horizontal foliation occurs if the vertical gradient (caused by the clutch zone) is larger and vertical foliation occurs where the horizontal gradient (caused by the wrenching) is larger.

\section{Kinematic examples of clutches}

\subsection{Wrench settings}

The idea of a clutch zone may be most applicable to the context of wrenching. Wrench is defined as simple shear deformation accommodating a distributed strike-slip motion. Wrench systems do not result in thickening or thinning so that the vertical distribution of lithospheric layers and the rheological layering are largely unchanged during deformation (e.g. McKenzie and Jackson, 1983). Additionally, the large thermal disturbances characteristic of extensional and contractional zones are not developed as severely. The wrench setting also emphasizes an additional complexity in that there are two sub-horizontal layers (upper and lower crust) lying above the lithospheric mantle.

Sub-horizontal shear zones are expected in dominantly wrench environments, despite the prevalence of vertical foliations in these settings (e.g. Fossen et al., 1994). The presence of sub-horizontal shear zones in wrench systems is an indication that the vertical displacement gradients are locally larger than the horizontal displacement gradients (Fig. 7). Consequently, the final fabrics are a combination of a vertical simple (or general) shear from the wrench movements and horizontal simple (or general) shear within the clutch zones (see Teyssier et al., this volume).

Does surface deformation in wrench settings indicate the presence of a clutch? Bourne et al. (1998a, b) used geodetic data to measure the displacement field within upper crustal blocks separated by discrete faults in the Marlborough fault system in New Zealand and the San Andreas system in southern California. They find that the present velocity field of upper crustal deformation corresponds well with the long-term, average velocity field determined from geological studies and relative plate motion (also Molnar et al., 1999, for New Zealand). Therefore, they suggest that the upper crustal blocks are dragged passively along with the viscously shearing lithospheric mantle. This argument was also made by England and Wells (1991), from the study of the paleomagnetically-determined rotation of the upper crust along western North America. These studies suggest that mechanical coupling exists between the lower and upper layers of the lithosphere; this coupling must take place in the ductile crust. We note that the Bourne et al. (1998a) model is not the only way to explain the geodetic data: Savage et al. (1999) explain the same geodetic measurements using a visco-elastic model driven by side boundary conditions.

\subsection{Transpressional settings}

Kinematic models of orogens have typically adopted the view of side-driven boundary conditions resulting from relative convergence/divergence of adjacent rigid blocks or plates. One prominent example is the transpression (and transtension) model of Sanderson and Marchini (1984) (Fig. 8a), in which deformation occurs between two rigid blocks that obliquely converge toward each other. We use transpression as a deformation model in this section, as it provides a good example of lithospheric-scale deformation, although other deformation models may also typify orogens.

Several authors (e.g. Schwerdtner, 1989; Robin and Cruden, 1994) have commented on the particular boundary 


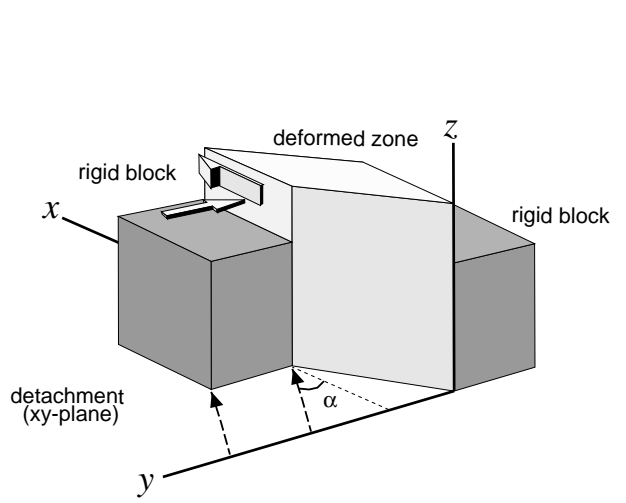

a. Wall-confined transpression - top view

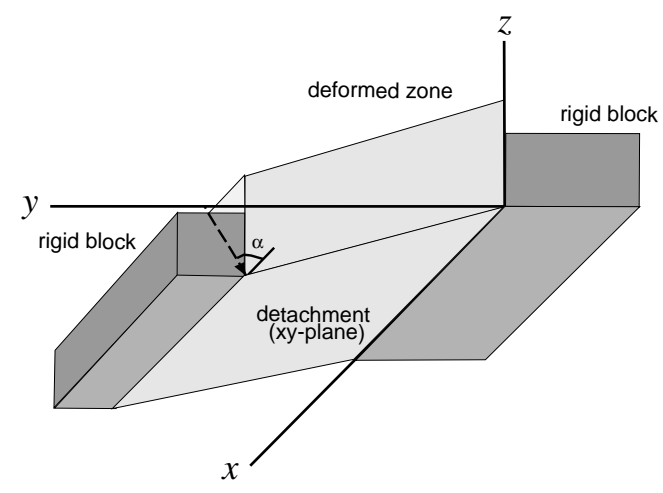

b. Wall-confined transpression - bottom view
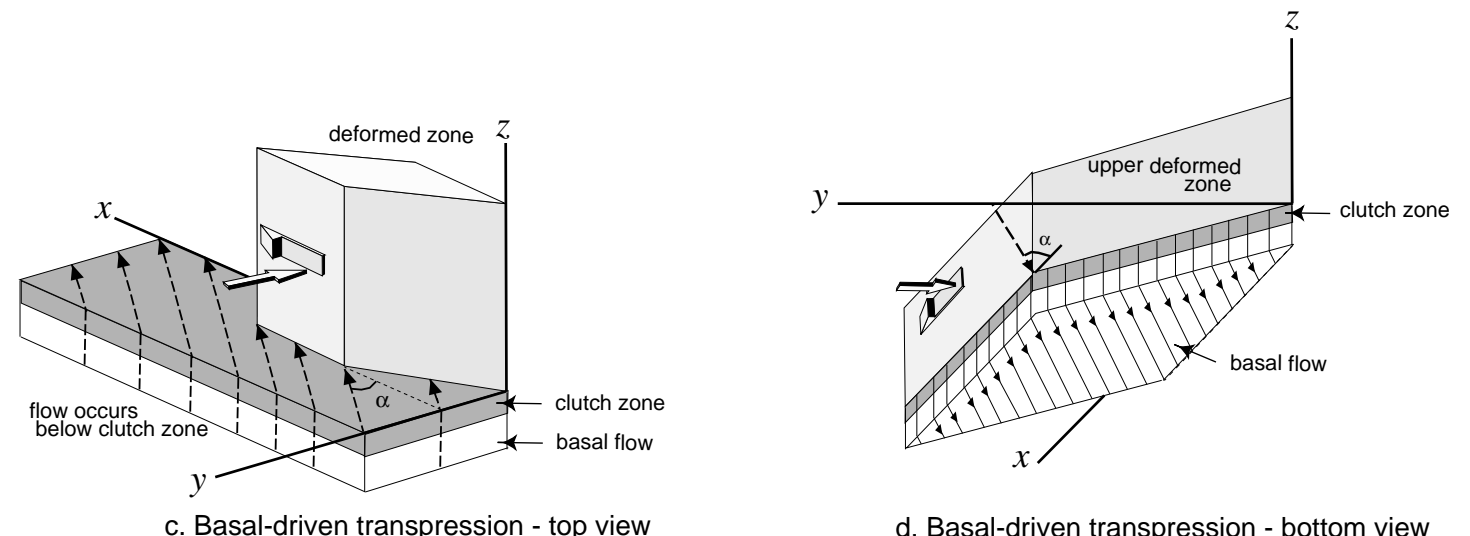

d. Basal-driven transpression - bottom view

Fig. 8. Transpression (in the sense of Sanderson and Marchini, 1984) occurring as a result of side boundary conditions (a,b) and basal boundary conditions (c, d). (a) Light gray material is the deforming zone between dark gray rigid walls. (b) Same as (a), except from a viewpoint in which the diagram is tilted away from the viewer. (c) Light gray material is the deforming zone as a result of basal flow. (d) Same as (c), except from a viewpoint in which the diagram is tilted away from the viewer. For (c) and (d), a clutch zone exists in the upper layer is shown in intermediate gray, and deformation within the upper layer only occurs over the clutch zone.

conditions of the bounding walls of these blocks. The walls allow upward and downward vertical extrusion with respect to the adjacent rigid blocks. In contrast, material in the deformation zone adheres to the wall for the horizontal motion. For the wrench component, the walls do not allow horizontal extrusion. Despite the difficulty with the boundary conditions of the walls, the predictions made for transpressional deformation match the observed geological structures in many obliquely-convergent settings. Consequently, it is worth re-examining the flow lines in such an obliquelyconvergent deforming zone to assess what other boundary conditions might result in transpressional kinematics.

In the absence of side-driven boundary conditions (i.e. walls), what determines the location of a deformation zone? In a bottom-driven system, deformation occurs where there is mechanical communication between the basal flow and the overlying material, i.e. through the clutch zone (Fig. 8c, d). Transpressional deformations are the only three-dimensional deformations that create straight and parallel flow lines in the horizontal plane, for any angle of convergence (e.g. Tikoff and Teyssier, 1994; Teyssier and Tikoff, 1998). For this reason, one could argue that the boundary conditions of transpressional deformations seem particularly appropriate to oro- genic belts. This deformation, however, can occur as a result of the bottom boundary conditions alone rather than the existence of side boundary conditions. This is essentially the concept of basally-controlled or "bottoms-up transpression" proposed by Teyssier and Tikoff (1998) and illustrated in Fig. 8d.

In the absence of mechanical interaction, the basal flow continues, a detachment surface forms at the base of the upper region and no deformation of the upper region occurs. Consequently, the flow in the basal layer could exist everywhere but is only transferred to the upper layer above the region where a basal traction or clutch exists.

\section{Attachment or detachment?}

The concept of detachments is well explored in the geological literature. Balancing the large amounts of contraction in thrust belts (e.g. Sevier thrust front) required the existence of mid- to lower-crustal detachments (or décollements) linking to the orogenic hinterland (e.g. Bally et al., 1966; Allmendinger et al., 1987; Oldow et al., 1989). Similar logic was also applied to orogenic-scale detachments in extension 
undeformed

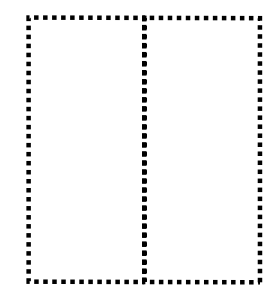

a.

b.

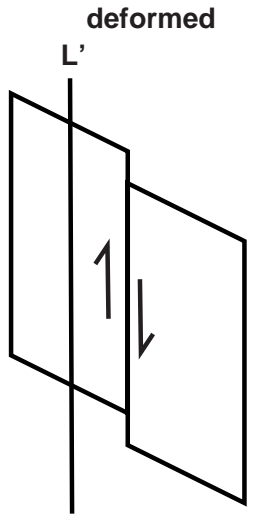

$\mathbf{L}$

\section{CROSS-SECTIONAL VIEW}

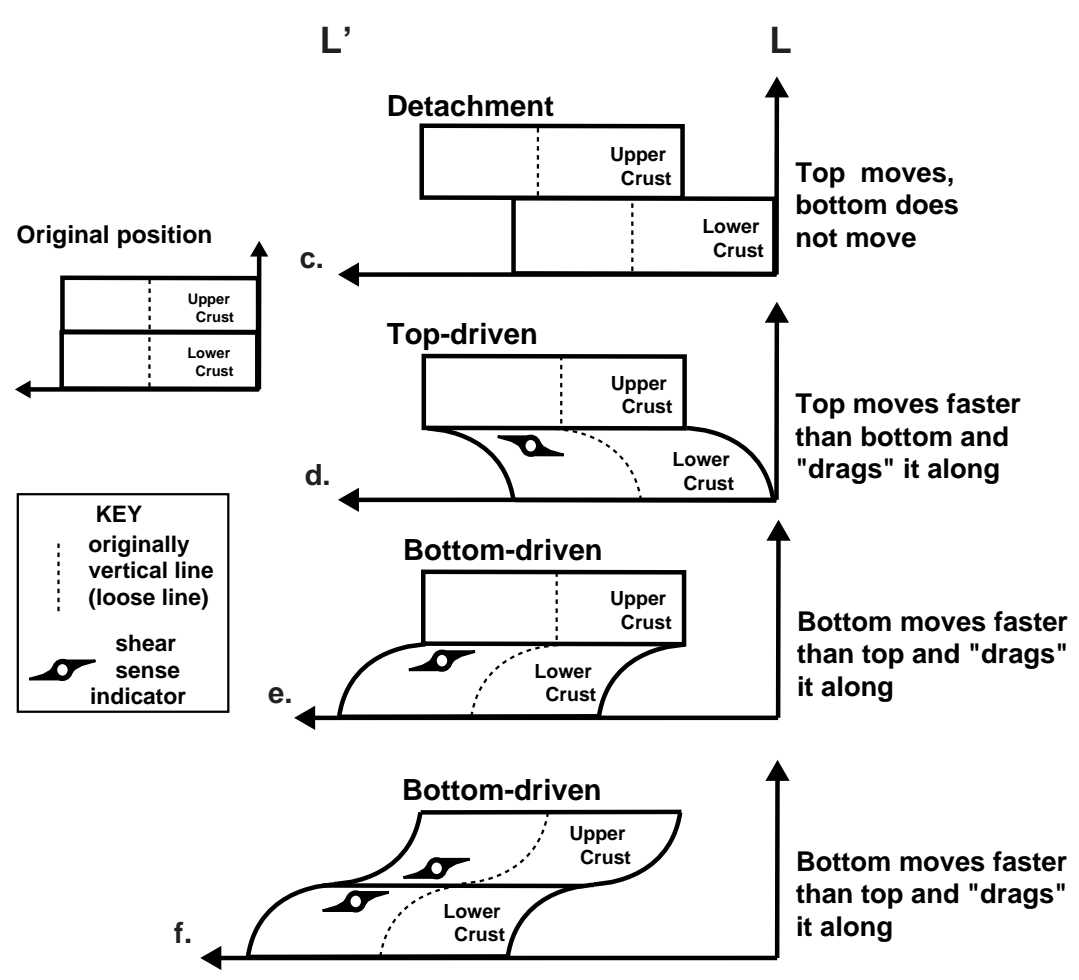

Fig. 9. Clutch zones between upper and lower crust in wrench systems. (a) Map view of system prior to deformation. (b) Map view of system during deformation, showing the orientation of cross section L-L', which is shown in (c)-(e). (c) No mechanical attachment between the two layers results in a discontinuity or detachment. (d) For top-driven systems, the top has larger displacement and moves the bottom part of the system via a clutch zone in the lower crust. (e) For bottom-driven systems, the bottom has larger displacement and moves the top part of the system through the clutch zone in the lower crust. (f) Another example of a bottom-driven system is one in which the clutch zone extends into the upper crust.

(Wernicke and Burchfiel, 1982). Note that we do not use the word "detachment" to refer to normal faults, as is common in the literature.

In contrast, the concept of crustal attachments is less well explored. Axen et al. (1998) proposed that shear zones found between the upper and lower crust in extensional systems act to couple these two layers. In their model, the deformation of the upper crust causes deformation of the lower crust. The clutch model seeks to explain the partial attachment in either a top-driven (e.g. Axen et al., 1998) or bottom-driven (e.g. Molnar, 1992) system.

Sub-horizontal shear zones are observed or inferred in several settings, including the Chugach complex, Alaska (Pavlis and Sisson, 1995), northeast Greenland (Strachan et al., 1992), and San Andreas fault system (e.g. Jones et al., 1994). These structures are inferred to separate upper and 
lower crustal domains, and to have a sub-horizontal orientation. These shear zones, although often interpreted as detachments, may act to partially couple the overlying and underlying material.

\subsection{How to determine?}

Despite the ambiguity of surface velocity fields in distinguishing between top-driven vs. bottom-driven systems, these differences are potentially resolvable with geological studies. One approach is to utilize shear sense indicators on the high-strain zones that bound the lithospheric layers, such as the wrench systems shown in Fig. 9. Fig. 9a, b shows two map views of a strike-slip partitioned wrench zone in an undeformed and deformed state, while Fig. 9c-f shows cross sections through the system. If one considers a cross section L-L', the sense of shear along the attachment layer changes depending on whether the system is decoupled, top-driven, or bottom-driven.

One can also potentially determine the difference by the nature of the localization zone. True attachment zones are ones that do not display relative displacement (i.e. there is no shear zone). Detachment surfaces, very localized zones of deformation, are surfaces with no attachment. In contrast to both of these, thick shear zones are zones of displacement gradients and therefore are allowing some percentage of relative coupling.

Another geological method for determining the presence of a clutch zone is to test for strain compatibility (e.g. Cutler and Elliott, 1983) across these high-strain horizons. Observations for the test would document the variation in fabrics away from the highest strain zone. Using this data to determine strain gradients and deformation history, one could determine if the kinematics in the lower strain areas are kinematically compatible with the high strain zones. If so, the fabrics are presumably related and require some level of coupling.

The main difficulty in evaluating clutch zones is the one that dominates most studies of mid- to lower-crustal rocks: lack of appropriate strain markers. Clutch zones, when either studied or modeled, may result in characteristic and recognizable patterns of deformation. Work on this is in the initial phases (e.g. Teyssier et al., this volume). However, the distinction between attachment zones, partial attachment (clutch) zones, and detachment zones is obtainable from geological data, provided enough constraints exist.

\section{Candidates for lithosperic clutch zones}

Figure 10 shows a vertical column of lithosphere undergoing heterogeneous simple shearing. Although this cartoon is conceptual, it suggests that high strain zones will be associated with rheological transitions in the lithosphere. Examples include the brittle-ductile (upper crust/lower crust) transition (e.g. Axen et al., 1998) and, to a lesser extent, the lower crust/upper mantle transition. Many studies indicate that the

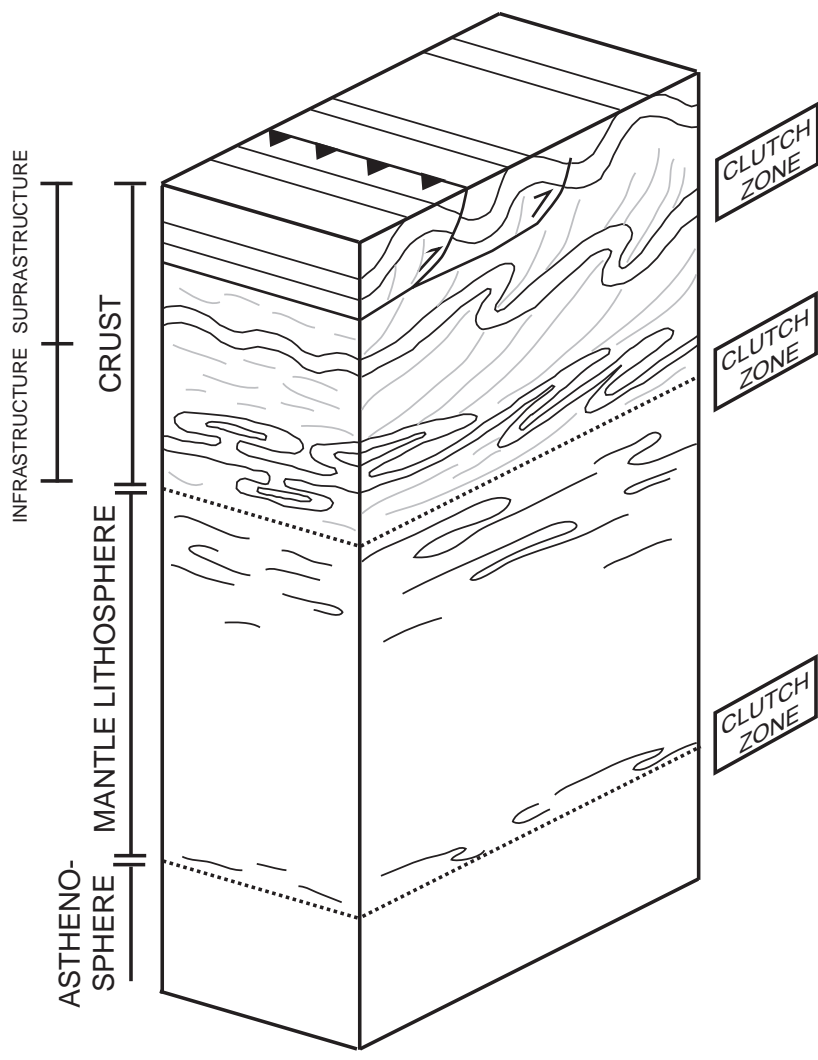

Fig. 10. Cartoon of the lithosphere and upper asthenosphere, illustrating the different behavior of different lithospheric levels. Strain and fabric development is concentrated at rheological boundaries, and it is these areas that clutch zones are hypothesized to occur. The difference in behavior across some rheological boundaries, such as the upper and lower crust (infrastructure vs. suprastructure), is well known in structural geology. Other transitions may also act as clutches.

upper crust/lower crust transition records high strain, presumably in an attempt to maintain kinematic and mechanical continuity. Consequently, we identify this transition as a possible clutch zone in the lithosphere. The common occurrence of sub-horizontal fabrics in exposures of lower crustal rocks are possible evidence of a clutch zone along the crust/mantle contact. Although we have no direct evidence, we further speculate that the lithosphere/asthenosphere boundary may also act as a clutch zone. Below we investigate in more detail some possible clutch zones that occur in the lithosphere.

6.1 Brittle / ductile transition: The transition from the suprastructure to the infrastructure

Structural geologists have long recognized that there is a major difference in structural style as one explores increasingly lower layers of the earth's crust (Fig. 10). These crustal domains were recognized in the early part of the 1900s (e.g. Wegmann, 1935), and called structural levels, étages (French, "floors"), and Stockwerke (German, "mine levels"). These levels are defined by the kinematic behavior of the 
Mount Hay area, Arunta Block, Central Australia

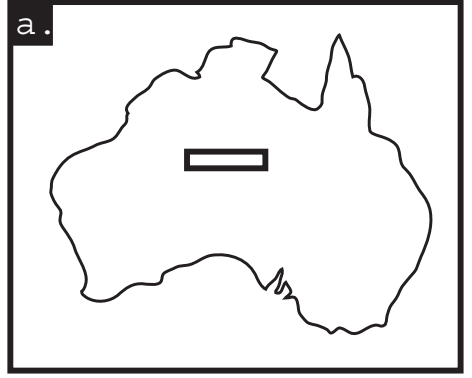

$133^{\circ} 00^{\prime} \mathrm{E}$

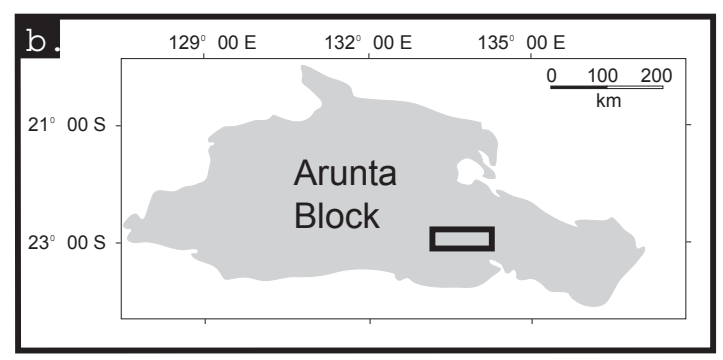

133010' E

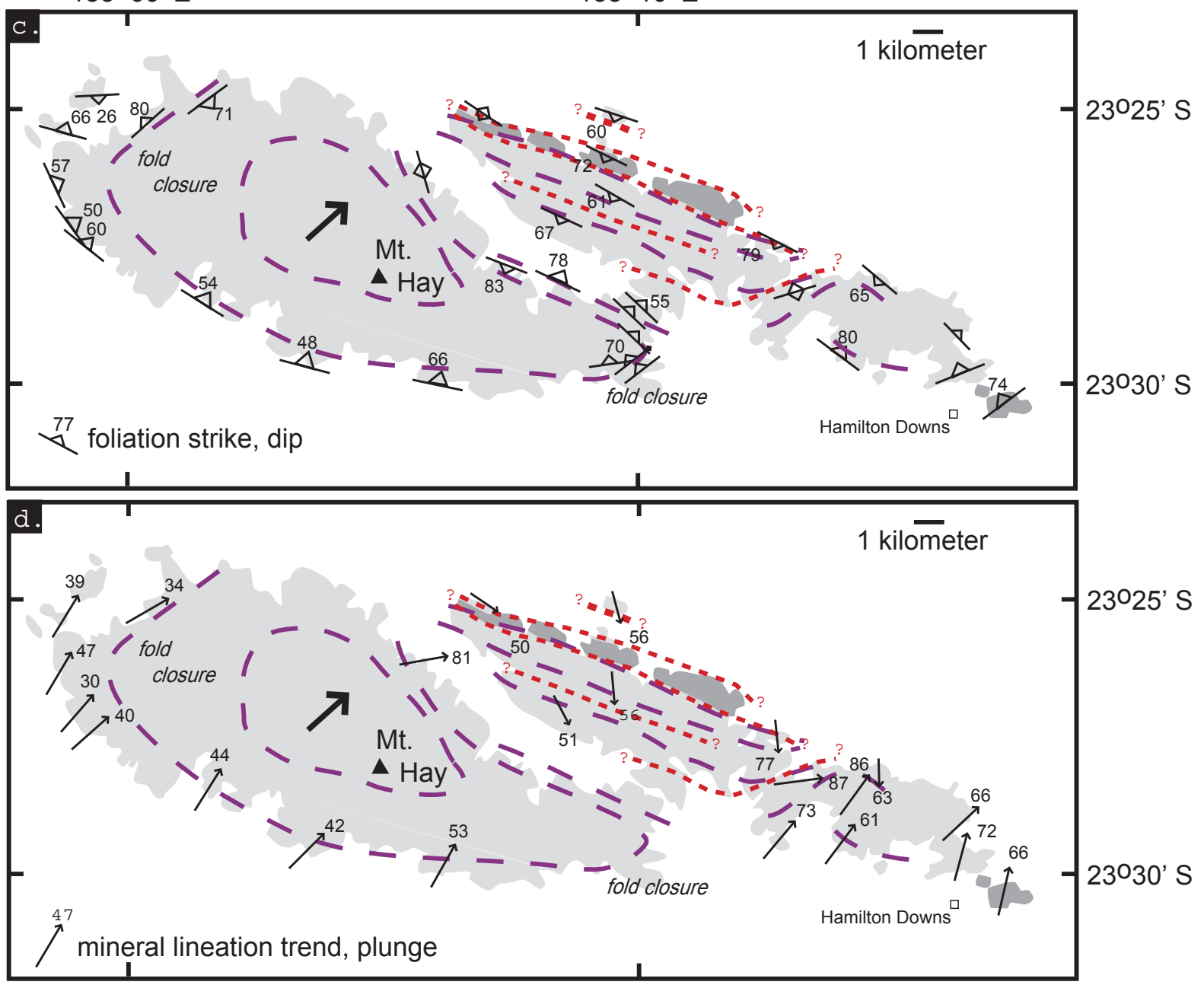

Fig. 11. The Mount Hay area in central Australia: (a) Location of the Arunta Block; (b) Location of the Mt. Hay block; (c) and (d) Simplified geological map of the Mt. Hay area, highlighting foliation and lineation, respectively. The Mt. Hay ridge is a 10-km scale sheath fold, suggesting that large strains are recorded in these granulites. Reconstruction of the granulite layering restores the sheath folds to a subhorizontal orientations. Darker gray, anorthositic granulite; lighter gray, pyroxene granulite; long dashed lines, foliation trace; short-dashed line, strain localization zone; arrow, approximate axis of sheath-like fold; open square, Hamilton Downs homestead. From Warren and Shaw (1995) and our field mapping.

rock bodies, independent of metamorphic grade, and are subhorizontal. Wegmann (1963) infered that the structures in each of the different structural levels formed simultaneously during orogenesis. Early workers made a distinction between an upper suprastructure with upright foliations and fold ax- ial planes, and lower infrastructure with flat-lying foliations and fold axial planes, and an intermediate level (e.g. de Sitter and Zwart, 1960). The transition between these levels are observed locally, such as in the Hercynian structures of the Pyrenees uplifted by Alpine tectonism (Carreras and Capela, 

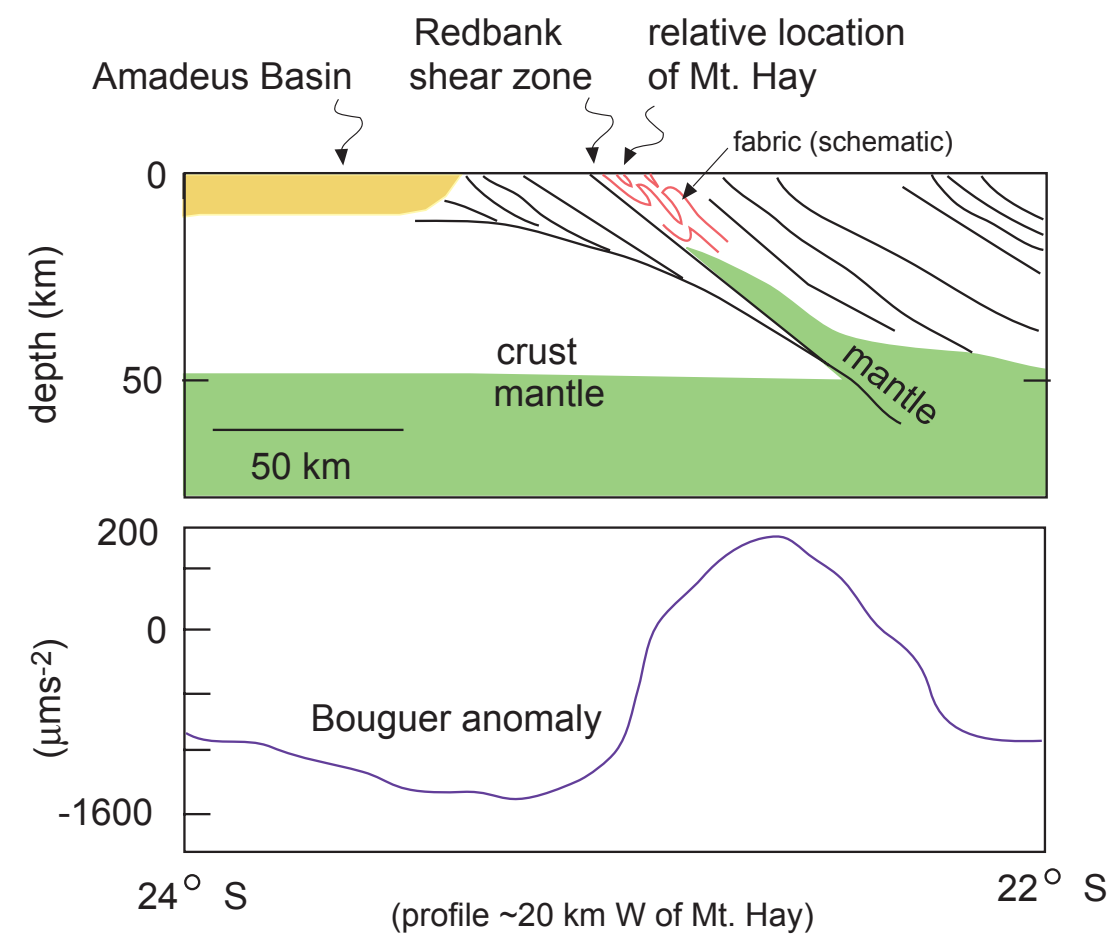

Fig. 12. Cross-section through the Redbank thrust zone, Arunta block, central Australia. Seismic and gravity data suggests that the currently steeply-dipping layering in the granulites is sub-parallel to the Moho, and thus the granulite layering restores to a sub-horizontal orientation. Modified from Korsch et al. (1998).

1994; Garcia-Sansegundo, 1996) and in the Hercynian structures of SW England (Zwart, 1963). An example from the South America/Caribbean boundary is addressed by Teyssier et al. (this volume).

6.2 Crust / mantle transition: Significance of flat-lying foliations and sheath folds

A major difficulty in evaluating the cause of deformation within continental crust is the lack of direct observation of the lowermost crustal levels. Crust/mantle transitions unaffected by later tectonic activity are observed in exhumed oceanic lithosphere, such as the basal part of obducted island arcs (e.g. Kohistan; Burg et al., 1998) and ophiolite sequences (e.g. Oman; Jousselin et al., 1998). Although crust/mantle transitions are typically dismembered or otherwise modified (e.g. Ivrea zone, Alps; Quick et al., 1995), good exposures of lower continental crust are exposed in a variety of localities, allowing us to make inferences about lower-crustal deformation.

Lower continental crust is typically composed of granulite facies rocks. In general, exposed granulite terranes share two distinguishing structural characteristics: They tend to have flat-lying foliation and contain abundant intrafolial folds ("transposed foliation") and/or sheath folds (e.g. Sandiford, 1986; Mosley, 1993; Kisters et al., 1997; Mitrofanov et al., 1998; Campos and Caby, 1999). If intrafolial or sheath folds develop principally by simple shear flow, they indicate extremely high shear strains in the lower continental crust (e.g. Cobbold and Quinquis, 1980; Vollmer, 1988). Consistent asymmetry of these structures, combined with subhorizontal foliation and lineation, indicates that shearing occurred in response to a vertical displacement gradient (i.e. a sub-horizontally oriented simple shear movement).

To illustrate this point, we concentrate on granulite exposed in the southern Arunta block of central Australia (Fig. 11). These granulites form the Bunghara (including Mount Hay) and Strangways metamorphic complexes, and part of the Harts Range, over a $\sim 300 \mathrm{~km}$ by $50 \mathrm{~km}$ area (Shaw and Langworthy, 1984; Shaw et al., 1994). The granulite terrane contains primarily mafic and quartzo-feldspathic gneisses, with minor amounts of pelitic gneisses, quartzites, and supra-crustal iron-formation rocks (Warren, 1983; Glikson, 1984; Shaw, et al., 1984; Goscombe, 1992). The highgrade tectonothermal event responsible for granulite facies structures occurred ca. 1.7 Ma (Collins and Shaw, 1995). The terrane was then exhumed during the Proterozoic Anmatjira $(\sim 1.4 \mathrm{Ga})$ and Paleozoic Alice Springs ( 300 Ma) events (Teyssier, 1985; Shaw and Black, 1991; Collins and Shaw, 1995). Retrogression to lower metamorphic facies is restricted to discrete shear zones (e.g. Redbank thrust zone) responsible for uplift of the terrane. Gravity and reflection seismic data indicate that these thrust faults root into the lithospheric mantle (Fig. 12; e.g. Goleby et al., 1989).

Traces of compositional layering allow recognition of $\mathrm{cm}$ to km-scale sheath folds (Mount Hay block; Fig. 11), which dominate the terrane (e.g. Goscombe, 1992; Watt, 1992). 
These folds and associated lineation and foliation are inclined $\sim 45$ degrees to the north-northeast. Reflection seismic data indicate that these structures continue at depth and join mantle reflectors with the same mean dip (e.g. Korsch et al., 1998).

If deformation accumulated by simple shearing (e.g. Goscombe, 1992), the presence of such pervasive and consistently oriented sheath folds requires large amounts of shear strain (typically $\gamma=10-100$ for the formation of sheath folds). Given the extent of the fabric across the exposed cross-section, at least $\sim 10 \mathrm{~km}$ of mid- to lower crust was affected. Using these parameters, a first-order estimate of $\sim 500 \mathrm{~km}$ ( $\gamma=50$ on a $10 \mathrm{~km}$ thick zone) displacement occurred on the zone. The lack of an appropriate geodynamic framework rules out the possibility of determining the tectonic setting uniquely; these fabrics could have occurred in an extensional, contractional, or wrench regime. However, several lines of evidence suggest that these fabrics originated sub-horizontally:

(1) Seismic data indicate that the granulite facies structures and the crust-mantle transition currently have the same orientation (Fig. 12). This is corroborated by Bouguer gravity anomalies.

(2) Given the estimated displacement, if the zone dipped gently in either direction as a result of contraction or extension, the large amount of strain in the zone would have juxtaposed very different crustal levels. Pressuretemperature data from this terrane indicate that this did not occur.

The above argument suggests that the granulite-facies fabrics were parallel to and bounded by the crust/mantle contact during the Proterozoic. In a sub-horizontal orientation, the high shear strain records the relative movement between a mid/upper-crustal block and the mantle. The wide zone of fabric development in granulites of the Arunta block suggests mechanical coupling between the upper crust and the uppermost mantle. Consequently, the presence of sub-horizontal structures in the lower crust suggests partial attachment to flow in response to movement of the underlying mantle.

\subsection{Lithosphere / asthenosphere transition}

As suggested by petrologic models and changes in elastic properties detected by seismic waves, a major rheological boundary presumably occurs between the lithosphere and asthenosphere. This boundary is locally exposed in ophiolite complexes, where the asthenosphere is interpreted as deforming the lithospheric mantle (e.g. Jousselin et al., 1998). However, the boundary is generally unavailable for direct structural observations in orogenic zones, and information must be interpreted from seismic data. In particular, we address two transcurrent/weakly transpressional plate margins (San Andreas system, Pacific-North America boundary; Trinidad, Caribbean-South American boundary), from which we infer the nature of the lithosphere/asthenosphere transition.
In the San Andreas region, Savage and Silver (1993) and Özalaybey and Savage (1995) interpret shear-wave splitting data in terms of two superimposed anisotropic layers. Interpretations of the delay time depend on estimates of both the total thickness of the deformed package and the amount and orientation of anisotropy. The tectonic significance of anisotropy in the lower layer is debatable (Özalaybey and Savage, 1995); its E-W fast polarization direction has been interpreted to be due to either strained asthenosphere or a fossil anisotropy preserved in the subducted old Farallon plate. The upper layer, recognized only in the vicinity of the SAF, contains a fast polarization direction exactly parallel to the surface trace of the fault system (1-1.5 second delay time). This upper layer is estimated to be $50-100 \mathrm{~km}$ wide and 115 $125 \mathrm{~km}$ thick (Fig. 13a; Teyssier and Tikoff, 1998). Given the relatively thin lithosphere on the North American side of the fault system (e.g. Furlong et al., 1989), the anisotropic layer measured by SKS splitting must consist of the mantle lithosphere plus some asthenosphere below the San Andreas system.

Large measured seismic anisotropy ( $\sim 2$ seconds of delay time) exists beneath Trinidad and northeast Venezuela (Russo et al., 1996). This highly anisotropic mantle has a fast polarization direction that is $\mathrm{E}-\mathrm{W}$, parallel to the main trend of the Caribbean-South America plate boundary zone and the major strike-slip faults in it. This zone has a $100 \mathrm{~km}$ minimum width and the best estimate of its vertical dimension is $\sim 200 \mathrm{~km}$ (Fig. 13b; Russo et al., 1996) suggesting that it extends beyond the base of the lithosphere into the asthenosphere. Russo et al. (1996) interpret these observations to indicate the presence of a broad E-W trending vertical mantle shear zone that underlies the surface plate boundary zone. Although it is not possible at present to determine the age of the mantle fabric that generates the strong seismic anisotropy, the correspondence in orientation between current motion and shear wave splitting suggests it is recent and probably active.

In both central California and Trinidad, the shear wave splitting is large enough that the asthenosphere is probably contributing to the splitting fabric. As shear wave splitting requires a crystallographic preferred orientation, ongoing deformation and fabric must exist in the uppermost part of the asthenosphere. The rheological behavior difference between parts of the asthenosphere deforming by dislocation creep vs. diffusion creep is likely to result in some relative movement. In analogy to deformation higher in the lithosphere, this would presumably occur along a clutch zone with a subhorizontal orientation. A clutch zone associated with the lithosphere/asthenosphere boundary and other levels higher up provides a mechanism for relaying asthenospheric flow to the surface. This structure would also explain the parallelism of the shear wave splitting fast directions, geodetic measurements, and the surface structures. Lithospheric xenoliths currently provide the another possibility for determining the nature of this transition (e.g. Christensen et al., 2001). 

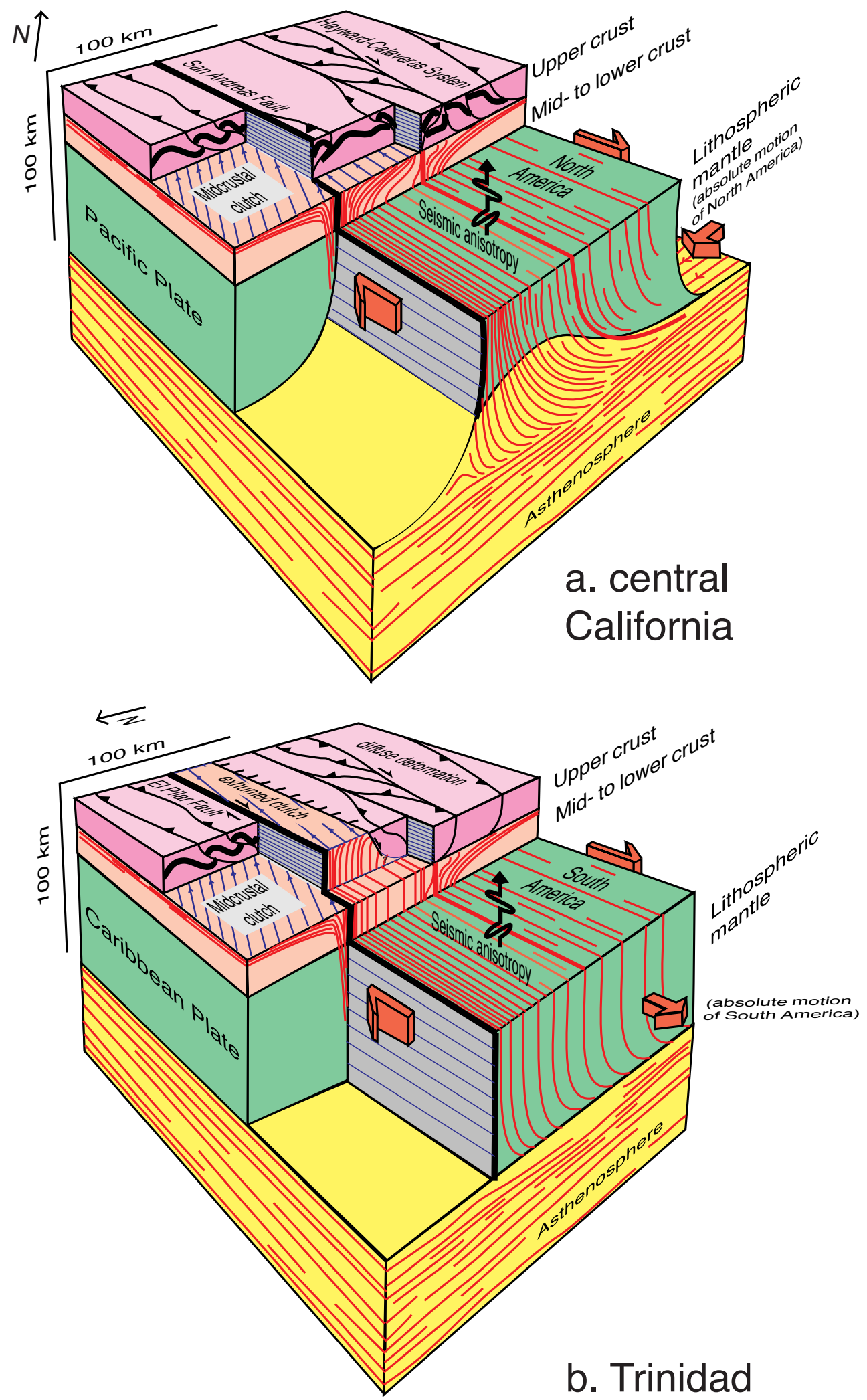

Fig. 13. Block diagrams of the San Andreas fault system in central California (Pacific/North American plate boundary) and the El Pilar fault system in Trinidad (Caribbean/South American plate boundary). Both boundaries are typified by diffuse surficial deformation and strong shear wave splitting. The coincidence of these two features suggests that deformation in the lithosphere, and possibly into the upper asthenosphere, is partially coupled. 
a. Initial condition prior to collapse

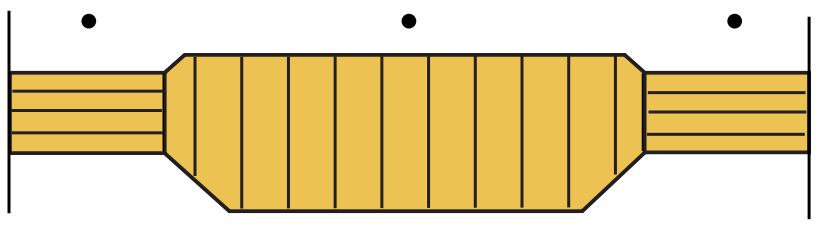

b. Upper crustal extension only

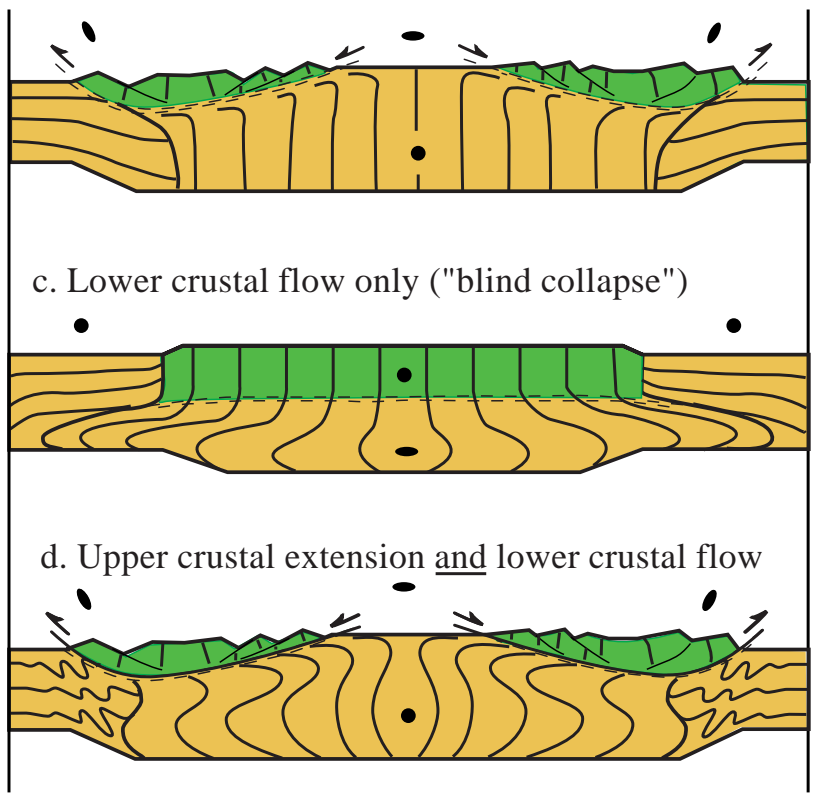

Fig. 14. From Rey et al. (2001). Gravitational instability caused by a thick crust could result in collapse, resulting in upper crustal extension (b; top-driven clutch), lower crustal flow (c; bottom-driven clutch), or a combination (d; locally either topor bottom-driven clutches). As most orogenies are hypothesized to form by bottom-driven systems, the occurrence of top-driven systems in collapse indicates a switch in deformation style.

\section{Discussion}

\subsection{Time dependence of top - vs. bottom-driven systems}

The model presented above is simplistic, particularly insofar as it assumes that both the thickness and the rheology of the lithosphere are constant through time. In orogens that have a non-negligible component of contraction across the plate margin, thickening of the crust and lithosphere introduces thermo-mechanical effects into the dynamics of the rheologic layers. One consequence of crustal thickening is thermal relaxation and time-dependent heating that may lead to melting of the lower crust. These effects would decrease the coupling between the crust and the upper mantle (Vanderhaeghe and Teyssier, 2001). Consequently, an orogenic system could start as a bottom-driven system and evolve to a top-driven system during crustal thickening (Fig. 14b).

However, top-driven collapse is not the only alternative for orogenic collapse (Rey et al., 2001). An alternative is to consider that the gravitational instability caused by a thick crust could result in lower crustal flow (Fig. 14c). In this case, the deformation remains a bottom-driven system, with the flowing lower crust flowing pulling along the overlying upper crust. If the upper crust remains undeformed, it can stay as a rigid lid on top of the collapsing system. It is most likely that both upper-crustal extension and lower-crustal flow occur simultaneously (e.g. Rey et al., 2001; Fig. 14d). Consequently, an orogenic belt may be simultaneously top- and bottom-driven, with the variation occurring on both a spatial and temporal basis. Analysis of sense of shear is critical to distinguish top- from bottom-driven systems.

\subsection{Clutch tectonics compared to other orogenic models}

Much of this article has attempted to document the bottomdriven boundary conditions of orogenic belts. However, this model is distinct from previous models of orogenic belts that assume some degree of bottom-driven boundary conditions. Probably the best known are the "conveyor-belt" models, which are successful at recreating geometries found in orogenic belts (e.g. Willet et al., 1993; Beaumont et al., 1996). These models require subduction zones to act as a conveyor belt to move the material toward each other. This requirement implies certain geometric elements, which include: 1) a singularity point at the junction of the subducting plate and the over-riding plate; 2) a backstop on the overriding plate; and 3) a rigid (non-deformed) and subducting uppermost mantle that is not involved in the deformation. The former two geometric elements may or may not be realistic in a deformation setting. However, the lattermost is inconsistent with upper mantle deformation evidenced by shear-wave splitting. Consequently, a subduction-type model involving a rigid mantle cannot explain the first-order observations in neotectonic zones.

The orogenic float model of Oldow et al. (1989) is similar to the clutch tectonics, insofar as both predict sub-horizontal shear zones. In both models, the displacement field at the base of the upper block (e.g. the crust) is controlled by the ratio of translation versus shortening. This idea was well illustrated for the orogenic float model, in which lineation orientation could vary between high strain zones (interpreted as décollements) at the base of the float. Varying fabric orientation at the base of the float is strictly a function of strike-slip partitioning within the orogenic wedge, and not associated with flow from below.

The clutch model differs from orogenic float models in that: 1) the deformation is driven from below by basal flow; and 2) there is some degree of attachment across the high strain zones. An orogenic float model inherently involves a detachment zone. In the case of any detachment, deformation is driven by side, rather than basal, boundary conditions in an orogenic float. While this model may describe parts of an orogenic belt, such as a foreland fold-and-thrust region which are underlain by a detachment horizon, it does not explain the coincidence of upper mantle and upper crustal deformation. This model, likewise, does not consider man- 
tle deformation, unless the detachment underlies the entire lithospheric plate.

\subsection{Clutch mechanisms in a plate tectonics context}

Clutch tectonics questions several aspects of classical plate tectonics. In particular, the notion of sub-horizontal partial attachment zones indicates that: 1) Horizontal displacement gradients in vertical planes are as significant as those in horizontal planes; and 2) Areas of coherent upper crustal movement (plates?) do not encompass the entire lithosphere. We address these two issues below.

Consider a vertical looseline that extends through the crust and adjacent mantle lithosphere. In the context of classical plate tectonics, this marker should remain straight and vertical at all times, except for a potential discontinuity at the lithosphere/asthenosphere boundary. This is particularly true in intra-plate settings. Within mountain belts, which are diffuse deformation zones, the assumption of lithospheric rigidity clearly does not apply.

Clutch tectonics predicts different behavior of a vertical looseline. Large vertical strain gradients suggest that the orientation of a marker must change from a vertical to an inclined position during deformation. This requires that the material in the upper crust moves relative to material in the lithospheric mantle. Alternatively stated, the vertical column that constitutes a lithospheric plate at any given location must change with time: Plates, as lithospheric entities, are not constant with time.

Another related aspect of clutch tectonics is that plate behavior, defined as a (upper-crustal) region with a distinct Euler pole relative to an adjacent region, are not spatially consistent at any instant in time. Consider a region that is undergoing vertical-axis rotation and/or translations, but no internal deformation (e.g. southern California; Luyendyk, 1991). Regardless of whether this block is side-driven or bottomdriven, it is moving relative to the underlying material. Thus, the rigid, plate-like behavior of these regions does not require that they are constituted of a coherent, attached lithosphere.

The notion of plate-like behavior requires that the plates consist of neither spatially- nor temporally-constant lithosphere. The difference of clutch tectonics vs. classical plate tectonics is simply the recognition of vertical strain gradients in the lithosphere, which are not predicted by a lithosphericscale plate approach. Classical plate tectonics is a kinematic theory designed largely to explain relative horizontal movements in a horizontal plane, whereas clutch tectonics emphasizes horizontal motions in a vertical plane.

A correlation of wide zones of active deformation and shear wave splitting exists in many neotectonic settings (San Andreas region, South Island of New Zealand, Tibet; Özalaybey and Savage, 1995; Teyssier and Tikoff, 1998; Molnar et al., 1999; Holt, 2000). Consequently, it appears that diffuse continental deformation is associated with pervasive internal deformation of the lithospheric mantle. As the brittle deformation of the upper crust is different from pervasive crystal-plastic flow of the mantle, the geometry of orogenic belts must reflect the varying responses of the distinct horizontal layering of the lithosphere. We hypothesize that it is the location of the clutch zones that controls the distribution of this diffuse deformation. As shear wave splitting probably has a contribution from asthenospheric mantle locally (e.g. Russo et al., 1996; Teyssier and Tikoff, 1997), a bottom-driven "clutch" system provides a possible connection between asthenospheric mantle flow and broad areas of diffuse continental deformation.

\section{Conclusions}

We propose a simple model to describe kinematic compatibility between the displacement fields of adjacent, but rheologically different, lithospheric layers. Clutch tectonics requires some coupling between adjacent lithospheric layers, and emphasizes that the role of sub-horizontal shear zones may be to partially attach, rather than detach, adjacent horizontal lithospheric layers. Both top-driven (gravity controlled) and bottom-driven (mantle flow controlled) systems are possible, although bottom-driven systems are considered as the general rule. We propose three main transitions that may act as lithospheric attachments: the brittle/ductile, crust/mantle, and lithosphere/asthenosphere transitions. Clutch zones can be recognized in nature by geological field studies that document appropriate shear sense indicators and strain gradients within sub-horizontal shear zones between different lithospheric layers.

Acknowledgements. Tim Little, Michelle Markley, Sarah Tindall, and Sarah Titus provided useful comments on versions of the manuscript. We thank Laurent Jolivet and an anonymous reviewer for helpful reviews of the manuscript. $\mathrm{BT}$ and $\mathrm{CW}$ were supported by a Packard fellowship.

\section{References}

Allmendinger, R. W., Hauge, T. A., Hanse, E. C., Potter, J. C., Kemper, S. L., Nelson, K. D., Knueper, P., and Oliver, J.: Overview of the COCORP $40^{\circ} \mathrm{N}$ transect, western United States - The fabric of an orogenic belt, Geological Society of America Bulletin, 98, 308-319, 1987.

Axen, G. J., Selverstone, J., Byrne, T., and Fletcher, J. M.: If the strong crust leads, will the weak crust follow? GSA Today, 8 , $1-8,1998$.

Bally, A. W., Gordy, P. L., and Stewart, G. A.: Structure, seismic data, and orogenic evolution of southern Canadian Rocky Mountains, Bulletin of Canadian Petroleum Geology, 14, 337381, 1966.

Beaumont, C., Kamp, P. J. J., Hamilton, J., and Fullsack, P.: The continental collision zone, South Island, New Zealand: Comparison of geodynamical models and observations, Journal of Geophysical Research, 101, 3333-3359, 1996.

Bourne, S. J., England, P. C., and Parsons, B.: The motion of crustal blocks driven by flow of the lower lithosphere and implications for slip rates of continental strike-slip faults, Nature, 391, 655659, 1998a. 
Bourne, S. J., Arnadottir, T., Beavan, J., Darby, D. J., England, P. C., Parsons, B., Walcott, R. I., and Wood, P. R.: Crustal deformation of the Marlborough fault zone in the South Island of New Zealand geodetic constraints over the interval 1982-1994, Journal of Geophysical Research, 103; 12, 30 147-30 165, 1998b.

Brace, W. F. and Kohlstedt, D. L.: Limits on lithospheric stress imposed by laboratory experiments, Journal of Geophysical Research, 85, 6248-6252, 1980

Burg, J. P., Bodinier, J. L., Chaudhry, S., Hussain, S., and Dawood, H.: Intra-arc mantle-crust transition and intra-arc mantle diapirs in the Kohistan Complex (Pakistani Himalaya); petro-structural evidence, Terra Nova, 10, 74-80, 1998.

Campos, N.M.C. and Caby, R.: Neoproterozoic high-pressure metamorphism and tectonic constraint from the nappe system south of the Sao Francisco Craton, Southeast Brazil, Precambrian Research, 97, 3-26, 1999.

Carreras, J. and Capela, I.: Tectonic levels in the paleozoic basement of the Pyrenees: a review and new interpretation, Journal of Structural Geology, 16, 1509-1524, 1994.

Christensen, N. I., Medaris, L. G., Wang, H. F., and Jelinek, E.: Depth variation of seismic anisotropy and petrology in central European lithosphere: A tectonothermal synthesis from spinel lherzolite, Journal of Geophysical Research, 2001.

Cobbold, P. R. and Quinquis, H.: Development of sheath folds in shear regimes, Journal of Structural Geology, 2, 1980.

Collins, W. J. and Shaw, R. D.: Geochronological constraints on orogenic events in the Arunta Inlier: a review, Precambrian Research, 71, 315-346, 1995.

Cutler, J. and Elliot, D.: The compatibility equations and the pole to the Mohr circle, Journal of Structural Geology, 5, 287-297, 1983.

England, P. G. and Wells, R. E.: Neogene rotations and quasicontinuous deformation of the Pacific Northwest continental margin, Geology, 19, 978-981, 1991.

Fossen, H., Tikoff, B., and Teyssier, C.: Strain modeling of transpressional and transtensional deformation, Norsk Geol. Tidsskrift, 74, 134-145, 1994.

Furlong, K. P., Hugo, W. D., and Zandt, G.: Geometry and evolution of the San Andreas Fault, Journal of Geophysical Research, 94, 3100-3110, 1989.

Garcia-Sansegungo, J.: Hercynian structure of the Axial Zone of the Pyrenees: the Aran Valley cross-section (Spain-France), Journal of Structural Geology, 18, 1315-1325, 1996.

Glikson, A. Y.: Granulite-gneiss terranes of the southwestern Arunta Block, central Australia: Glen Helen, Narwietooma, and Anburla 1:100 000 sheet areas, Bureau of Mineral Resources, Australia, Record 1984/22, 1984.

Goleby, B. R., Shaw, R. D., Wright, C., Kennett, B. L. N., and Lambeck, K.: Geophysical evidence for "thick-skinned" crustal deformation in central Australia, Nature, 337, 325-330, 1989.

Goscombe, B.: Intense non-coaxial shear and the development of mega-scale sheath folds in the Arunta block, central Australia, Journal of Structural Geology, 13, 299-318, 1992.

Holt, W. E.: Correlated crust and mantle strain fields in Tibet, Geology, 28, 67-70, 2000.

Ildefonse, B., Billiau, S., and Nicolas, A.: A detailed study of mantle flow away from diapirs in the Oman ophiolite, in: Vissers, R. L. M. and Nicolas, A. (Eds.): Mantle and lower crust exposed in ocean ridges and in ophiolites, Kluwer, 163-177, 1995.

Jones, D. L., Graymer, R., Wang, C., McEvilly, T. V., and Lomax, A.: Neogene transpressive evolution of the California Coast Ranges, Tectonics, 13, 561-574, 1994.
Jousselin, D., Nicolas, A., and Boudier, F.: Detailed mapping of a mantle diapir below a paleo-spreading center in the Oman opiolite, Journal of Geophsical Research, 103, 18 153-18 170, 1998.

Kisters, A.F.M., Gibson, R. L., Charlsworth, E. G., and Anhaeusser, C. R.: The origin of megabreccias in the Okiep copper district, South Africa - insights into mechanisms of melt migration at mid- to lower-crustal levels, Information Circular - University of the Witwatersrand, Economic Geology Research Unit., University of the Witwatersrand, Johannesburg, South Africa, 315, 23, 1997.

Kohlstedt, D. L., Evans, B., and Mackwell, S. J.: Strength of the lithosphere: Constraints imposed by laboratory experiments, Journal of Geophysical Research, 100, 17 587-17 602, 1995.

Korsch, R. J., Goleby, B. R., Leven, J. H., and Drummond, B. J.: Crustal architecture of central Australia based on deep crustal reflection profiling, in: Klemperer, S. L. and Mooney, W. D. (Eds.): Deep seismic profiling of the continents: II. A global survey, Tectonophysics, 288, 57-69, 1998.

Luyendyk, B. P.: A model for Neogene crustal rotations, transtension, and transpression in southern California, Geological Society of America Bulletin, 103, 1528-1536, 1991.

McKenzie, D. and Jackson, J.: The relationship between strain rates, crustal thickening, paleomagnetism, finite strain and fault movements within a deforming zone, Earth and Planetary Science Letters, 65, 182-202, 1983.

Mitrofanov, F. P., Sharov, N. V., Zagorodny, V. G., Glaznev, V. N., and Korja, A. K.: Crustal structure of the Baltic Shield along the Pechenga-Kostomuksha-Lovisa geotraverse, International Geology Review, 40, 990-997, 1998.

Molnar, P.: Brace-Goetze strength-profiles, the partitioning of strike-slip and thrust faulting at zones of oblique convergence, and the stress-heat flow paradox of the San Andreas fault, in: Evans, B. and Wong, T.-F. (Eds.): Fault mechanics and transport properties of rocks, Academic Press, 435-459, 1992.

Molnar, P., Anderson, H. J., Audoine, E., Eberhart-Phillips, D., Gledhill, K. R., Klosko, E. R., McEvilly, T. V., Okaya, D., Savage, M. K., Stern, T., and Wu, F. T.: Continuous deformation versus faulting through the continental lithosphere of New Zealand, Science 286, 516-519, 1999.

Mosley, P. N.: Geological evolution of the late Proterozoic "Mozambique Belt" of Kenya, Tectonophysics, 221, 223-250, 1993.

Nicolas, A. and Christensen, N. I.: Formation of anisotropy in upper mantle peridotites; a review, in: Fuchs, K. and Froidevaux, C. (Eds.): Composition, structure, and dynamics of the lithosphereasthenosphere system, Geodynamics Series, 16, 111-123, 1987.

Oldow, J. S., Bally, A. W., Avé Lallemant, H. G., and Leeman, W. P.: Phanerozoic evolution of the North American Cordillera: United States and Canada, in: Bally, A. W. and Palmer, A. R. (Eds.): The Geology of North America: an Overview, Geol. Soc. Am., Boulder, 139-232, 1989.

Özalaybey, S. and Savage, M. K.: Shear-wave splitting beneath western United States in relation to plate tectonics, Journal of Geophysical Research, 100, 18 135-18 149, 1995.

Pavlis, T. L. and Sisson, V. B.: Structural history of the Chugach metamorphic complex in the Tana River region, eastern Alaska: A record of Eocene ridge subduction, Geological Society of America Bulletin, 107, 1333-1355, 1995.

Quick, J. E., Sinigoi, S., and Mayer, A.: Emplacement of mantle peridotite in the lower continental crust, Ivrea-Verbano Zone, Northwest Italy, Geology, 23, 739-742, 1995.

Rey, P., Vanderhaeghe, O., and Teyssier, C.: Gravitational col- 
lapse of continental crust: Definitions, regimes, mechanisms and modes, Tectonophysics, 342, 435-449, 2001.

Robin, P.-Y.F. and Cruden, A. R.: Strain and vorticity patterns in ideally ductile transpression zones, Journal of Structural Geology, 16, 447-466, 1994.

Russo, R. M., Silver, P. G., Franke, M., Ambeh, W. B., and James, D. E.: Shear-wave splitting in northeast Venezuela, Trinidad, and the eastern Caribbean, Physics of the Earth and Planetary Interiors 95, 251-275, 1996.

Sanderson, D. and Marchini, R. D.: Transpression, Journal of Structural Geology, 6, 449-458, 1984.

Sandiford, M.: Horizontal structures in granulite terrains; a record of mountain building or mountain collapse? Geology, 17, 449452, 1986.

Savage, M. K. and Silver, P. G.: Mantle deformation and tectonics: constraints from seismic anisotropy in western United States, Physics of the Earth and Planetary Interiors, 78, 207-27, 1993.

Savage, J. C., Svarc, J. L., and Prescott, W. H.: Geodetic estimates of fault slip rates in the San Francisco Bay area, Journal of Geophysical Research, 104, 4995-5002, 1999.

Schwerdtner, W. M.: The solid-body tilt of deformed paleohorizontal planes: application to an Archean transpression zone, Journal of Structural Geology, 11, 1021-1027, 1989.

Shaw, R. D. and Langworthy, A. P.: Strangways range region, northern territory, 1:100 000, map commentary, Bur. Miner. Resour. Aust., Geol. Geophys. and map, 1984.

Shaw, R. D., Stewart, A. J., and Rickard, M. J.: Arltunga-Harts range region, northern territory, 1:100000, map commentary, Bur. Miner. Resour. Aust., Geol. Geophys. and map, 1984.

Shaw, R. D. and Black, L. P.: History and tectonic implications of the Redbank Thrust Zone, central Australia, based on structural, metamorphic, and Rb-Sr isotopic evidence, Australian Journal of Earth Science, 31, 457-484, 1991.

Silver, P. G.: Seismic anisotropy beneath the continents: Probing the depths of geology, Annual Review of Earth and Planetary Sciences, 24, 385-432, 1996.

Sitter, L. U. de and Zwart, H. J.: Tectonic development in supraand infra-structures of a mountain chain, 21st International Geological Congress, Copenhagen, 18, 249-256, 1960.

Strachan, R. A., Holdsworth, R. E., Friderichsen, J. D., and Jepsen,
H. F.: Regional Caledonian structure within an oblique convergence zone, Dronning Louise Land, NE Greenland, Journal of Geological Society of London 149, 359-371, 1992.

Teyssier, C.: A crustal thrust system in an intracratonic tectonic environment, Journal of Structural Geology, 7, 689-700, 1985.

Teyssier, C. and Tikoff, B.: Strike-slip partitioned transpression of the San Andreas fault system: a lithospheric scale approach, in: Holdsworth, R. E., Strachan, R. A., and Dewey, J. F. (Eds.): Continental transpression and transtension tectonics, Geological Society of London Special Publication, 135, 143-158, 1998.

Tikoff, B. and Teyssier, C.: Strain modeling of displacement-field partitioning in transpressional orogens, Journal of Structural Geology, 16, 1575-1588, 1994.

Vanderhaeghe, O. and Teyssier, C.: Crustal scale rheological transitions during late-orogenic collapse, Tectonophysics, 335, 211 $228,2001$.

Vauchez, A. and Mainprice, D. (Eds.): Physics of the Earth and planetary interiors: Seismic anisotropy, structures, and geodynamics of the continents, 23-309, 1996.

Vollmer, F. W.: A computer model of sheath-folds in shear regimes, Journal of Structural Geology, 10, 753-743, 1988.

Warren, R. G.: Metamorphic and tectonic evolution of granulites, Arunta Block, central Australia, Nature, 305, 300-303, 1983.

Warren, R. G. and Shaw, R. D.: Hermmansburg, Northern Territory 1:250000 Geological Series, Bureau Mineral Resources of Australia Explanatory Notes SF/53 and map, 1995.

Watt, G.: Geology of the Mount Hay - Mount Chapple massif (Arunta Block, Hermannsburg 1:250000 Sheet area, central Australia): field report, 1990. Bureau Mineral Resources of Australia, Record 1992/22, 1992.

Wernicke, B. and Burchfield, C.: Modes of extensional tectonics, Journal of Structural Geology, 4, 105-115, 1982.

Wegmann, C. E.: Tectonic patterns at different levels, Geological Society of South Africa, 115 Annexure, 76 p., 1963.

Willet, S., Beaumont, C., and Fullsack, P.: Mechanical model for the tectonics of doubly vergent compressional orogens: Geology, 21, 371-374, 1993.

Zwart, H. J.: The development of successive structures in the Devonian and Carboniferous of Devon and Cornwall, Geologie en Mijnbouw, 43, 516-526, 1963. 